\title{
PERBEDAAN PERSEPSI PETANI TERHADAP PROGRAM KARTU TANI DI KECAMATAN KALIJAMBE KABUPATEN SRAGEN
}

\author{
Koko Widyat Moko*, Suwarto dan Bekti Wahyu Utami \\ Program Studi Penyuluhan dan Komunikasi Pertanian, Fakultas Pertanian, Universitas Sebelas Maret \\ *Corresponding author: kokowidyatmoko@student.uns.ac.id
}

\begin{abstract}
The aims of this research is to analyze the differences in the farmers' perception to Farmers' Card program in Kalijambe District Sragen Regency based on the environment of farmers among the farmers who have long distance access from the District Office and Bank BRI with the farmers who have at close range access from the District Office and Bank BRI and based on the position of farmers in farmers' group, they are management and members of farmers' group. The basic method of this research is descriptive quantitative and survey techniques. The method of Location determination was done purposively in Kalijambe District Sragen Regency by taking two farmer groups they are farmers' group Tani Santoso Banaran village and farmers' group Ngudi Mulyo Wonorejo village. The population of this research was a farmer who is included/listed in the program Farmers' Cards in Kalijambe District Sragen Regency, with the number of farmers' responder 60 peoples. The sample is determined by using multi-stage cluster random sampling. The Analysis of data used is the different test of U Mann Whitney. The results showed that there were significant differences in the perception of the Farmers' Card program based on the environment of farmers and farmers' position in farmers' group. The differences of perceptions based on their environment showed that the farmers' perception whose close access to the District Office and Bank BRI is better than the perception of farmers whose long distance access from the District Office and Bank BRI. Based on the farmers' position in farmers' group, it is showed that the farmers' perception in farmers' management is better than the farmers ' perception in farmers' member.
\end{abstract}

Keywords: Farmers' card program; Farmers' group; Perception differences

Cite this as: Moko, K., Suwarto, S., \& Utami, B. 2017. Perbedaan Persepsi Petani terhadap Program Kartu Tani di Kecamatan Kalijambe Kabupaten Sragen. Caraka Tani: Journal of Sustainable Agriculture. 32(1), 9-13. doi: http://dx.doi.org/10.20961/carakatani.v32i1.15926

\section{PENDAHULUAN}

Pembangunan pertanian di Indonesia bertujuan untuk mensejahterakan petani melalui subsidi input usaha tani (pupuk, benih) maupun penerapan tekhnologi baru sehingga diharapkan dapat meningkatkan produksi pertanian. Permasalahan yang terjadi terkait pupuk meliputi kelangkaan pupuk, harga yang fluktuatif serta penggunaan pupuk oleh petani yang sering kali melebihi dosis anjuran. Kelangkaan pupuk bersubsidi terjadi karena kebutuhan akan pupuk yang tinggi sedangkan ketersediaan di tingkat pengecer/penjual serta distributor yang rendah, bahkan seringkali ketika dibutuhkan tidak ada mengakibatkan harga pupuk yang semakin meningkat. Hal tersebut karena ketidak merataan akan distribusi pupuk bersubsidi baik di tingkat distributor wilayah maupun di tingkat petani.

Upaya Provinsi Jawa Tengah dalam penanganan terkait pupuk bersubsidi yaitu melalui program Kartu Tani. Kartu Tani adalah kartu debit BRI co-branding yang digunakan secara khusus untuk membaca alokasi Pupuk Bersubsidi dan transaksi pembayaran Pupuk Bersubsidi di mesin Electronic Data Capture (EDC) BRI (Bank Rakyat Indonesia) yang ditempatkan di pengecer serta dapat berfungsi untuk melakukan seluruh transaksi perbankan pada umumnya.

Kecamatan Kalijambe Kabupaten Sragen merupakan salah satu kecamatan yang telah menjalankan program Kartu Tani. Kecamatan Kalijambe sebagai lokasi penelitian berdasarkan beberapa pertimbangan seperti keadaan wilayah, 
potensi sumber daya alam, lingkungan petani, serta dukungan instansi terkait. Disamping itu, keadaan wilayah Kecamatan Kalijambe memungkinkan untuk dapat membandingkan persepsi petani berdasarkan akses jarak desa terhadap kantor kecamatan dan Bank BRI setempat.

Penting untuk di kaji terkait perbedaan persepsi petani terhadap program Kartu Tani karena persepsi akan menentukan keberhasilan dan keberjalanan suatu program, petani sebagai pelaku utama program Kartu Tani akan menentukan keikutsertaan terhadap program Kartu Tani berdasarkan pandangan dan penilaian terhadap program tersebut.

Penelitian ini bertujuan untuk;

Menganalisis perbedaan persepsi petani terhadap program Kartu Tani di Kecamatan Kalijambe berdasarkan lingkungan petani antara petani yang jarak akses jauh dari Kantor Kecamatan dan Bank BRI dengan petani yang jarak akses dekat dari Kantor Kecamatan dan Bank BRI. (2) Menganalisis perbedaan persepsi petani terhadap program Kartu Tani di Kecamatan Kalijambe berdasarkan kedudukan petani dalam kelompok tani yaitu pengurus dan anggota.

\section{METODE PENELITIAN}

Metode penelitian dirancang dengan pendekatan deskriptif kuantitatif. Menurut Achmadi dan Narbuko (2003) metode deskriptif yaitu metode penelitian yang berusaha menuturkan pemecahan masalah yang ada sekarang berdasarkan data, sehingga penelitian ini juga menyajikan data, menganalisis, dan menginterpretasi. Penelitian dilakukan dengan menggunakan teknik survei. Menurut Suyanto dan Sutinah (2007) penelitian survei memiliki ciri khas yang ditunjukkan dari jumlah sampel (yang dijadikan sasaran pengamatan) cukup besar, dan cara pengumpulan datanya yang dilakukan dengan menggunakan perangkat kuisioner.

Lokasi penelitian dipilih secara sengaja (purposive) yaitu Kecamatan Kalijambe Kabupaten Sragen. Sampel ditentukan dengan teknik multi stage cluster random sampling, didapat 2 kelompok tani yaitu kelompok tani Tani Santoso Desa Banaran dengan jarak akses terdekat dari Kantor Kecamatan dan Bank BRI dan kelompok tani Ngudi Mulyo Desa Wonorejo dengan jarak akses terjauh dari Kantor Kecamatan dan Bank BRI. Pengambilan sampel sebanyak
60 petani responden. Data dalam penelitian ini adalah data primer dan sekunder dengan menggunakan teknik observasi, wawancara, dan dokumentasi.

Data yang telah didapat akan dianalisa untuk menguji apakah terdapat perbedaan dari dua kelompok independen yang ditarik dari populasi yang sama. Untuk mengetahui perbedaan persepsi petani terhadap program Kartu Tani menggunakan uji beda yaitu U Mann-Whitney dengan rumus:

$$
\mathrm{U}=\mathrm{n}_{1} \mathrm{n}_{2}+\frac{\mathrm{n}_{2}\left(\mathrm{n}_{2}+1\right)}{2}-R 2
$$
Keterangan:
$\mathrm{U} \quad=$ koefisien Mann-Whitney
$\mathrm{n}_{1} \quad=$ Jumlah sampel penelitian 1
$\mathrm{n}_{2}=$ Jumlah sampel penelitian 2
$\mathrm{R}_{2}=$ jumlah ranking yang diberikan kepada kelompok yang ukuran sampelnya $\mathrm{n}_{2}$

Pengujian kesignifikanan mann-whitney $\left(\mathrm{n}_{2}\right)>$ 20, menggunakan rumus:

$$
Z=\frac{U-\frac{n_{1} n_{2}}{2}}{\sqrt{\frac{\left(n^{1}\right)\left(n^{2}\right)\left(n^{1}+n^{2}+1\right)}{12}}}
$$

\section{Kriteria pengambilan keputusan perbedaan persepsi petani berdasarkan lingkungan petani:}

Jika $\mathrm{z}$ hitung $>\mathrm{z}$ tabel $(a=0,05)$, maka $\mathrm{H}_{0}$ ditolak dan $\mathrm{H}_{1}$ diterima, berarti terdapat perbedaan persepsi yang signifikan terhadap program Kartu Tani antara petani yang jarak akses jauh dari Kantor Kecamatan dan Bank BRI dengan petani yang jarak akses dekat dari Kantor Kecamatan dan Bank BRI.

Jika $\mathrm{z}$ hitung $\leq \mathrm{z}$ tabel $(a=0,05)$; maka $\mathrm{H}_{0}$ diterima dan $\mathrm{H}_{1}$ ditolak, berarti tidak terdapat perbedaan persepsi yang signifikan terhadap program Kartu Tani antara petani yang jarak akses jauh dari Kantor Kecamatan dan Bank BRI dengan petani yang jarak akses dekat dari Kantor Kecamatan dan Bank BRI.

\section{Kriteria pengambilan keputusan perbedaan persepsi petani berdasarkan kedudukan petani di kelompok tani :}

Jika $\mathrm{z}$ hitung $>\mathrm{z}$ tabel $(a=0,05)$, maka $\mathrm{H}_{0}$ ditolak dan $\mathrm{H}_{1}$ diterima, berarti terdapat 
perbedaan persepsi yang signifikan terhadap program Kartu Tani antara pengurus kelompok tani dengan anggota kelompok tani.

Jika $\mathrm{z}$ hitung $\leq \mathrm{z}$ tabel $(a=0,05)$; maka $\mathrm{H}_{0}$ diterima dan $\mathrm{H}_{1}$ ditolak, berarti tidak terdapat perbedaan persepsi yang signifikan terhadap program Kartu Tani antara pengurus kelompok tani dengan anggota kelompok tani.

\section{HASIL DAN PEMBAHASAN}

Coleman and Hemsworth (1998) dalam Kilic dan Bozkurt (2013) menyatakan bahwa perbedaan antara persepsi petani dapat menjadi alasan untuk perbedaan pemahaman petani serta moral petani yang menjadi dasar persepsi, sehingga berpengaruh terhadap kesejahteraan mereka.

Tabel 1. Hasil Analisis Uji Beda

\begin{tabular}{|c|c|c|c|c|c|}
\hline No. & $\begin{array}{c}\text { Perbedaan Persepsi Petani Terhadap } \\
\text { Program Kartu Tani } \\
\end{array}$ & $\mathrm{N}$ & $\begin{array}{c}\text { Mann- } \\
\text { Whitney }\end{array}$ & $\begin{array}{l}\text { Asymp. Sig } \\
\text { (2-tailed) }\end{array}$ & $Z_{\text {hit }}$ \\
\hline 1 & $\begin{array}{l}\text { Petani dengan jarak terjauh dari Kantor } \\
\text { Kecamatan dan Bank BRI }\end{array}$ & 30 & \multirow{2}{*}{225,000} & \multirow{2}{*}{0,001} & \multirow{2}{*}{$-3,331$} \\
\hline & $\begin{array}{l}\text { Petani dengan jarak terdekat dari Kantor } \\
\text { Kecamatan dan Bank BRI }\end{array}$ & 30 & & & \\
\hline 2 & Anggota kelompok tani & 52 & \multirow{2}{*}{33,000} & \multirow{2}{*}{0,000} & \multirow{2}{*}{$-3,810$} \\
\hline & Pengurus kelompok tani & 8 & & & \\
\hline
\end{tabular}

Sumber: Analisis Data Primer 2017

Keterangan: $\alpha \quad: 0,05$

$Z_{\text {hit }} \quad:$ Z hitung

$Z_{\text {tabel }} \quad: 1,96(\alpha: 0,05)$

Perbedaan Persepsi Petani terhadap Program Kartu Tani berdasarkan Lingkungan Petani (Petani yang jarak akses jauh dari Kantor Kecamatan dan Bank BRI dengan Petani yang jarak akses dekat dari Kantor Kecamatan dan Bank BRI)

Tabel 1 menunjukkan bahwa terdapat perbedaan persepsi yang signifikan terhadap program Kartu Tani berdasarkan lingkungan petani antara petani yang jarak aksesnya jauh dari Kantor Kecamatan dan Bank BRI dengan petani yang jarak aksesnya dekat dengan Kantor Kecamatan dan Bank BRI. Hal ini menunjukkan bahwa persepsi petani yang jarak akses dekat dengan Kantor Kecamatan dan Bank BRI lebih baik dari persepsi petani yang jarak akses jauh dari Kantor Kecamatan dan Bank BRI.

Perbedaan persepsi tersebut berhubungan dengan beberapa faktor meliputi pengertian program, manfaat program, dan kegiatan program. Pada pengertian program petani dengan jarak yang dekat dari akses informasi cenderung lebih cepat dan lebih jelas dari petani dengan jarak yang jauh dari akses informasi, sehingga petani dengan jarak yang dekat dari akses informasi relatif lebih paham dan tentu berpersepsi lebih baik terkait program Kartu Tani. Terkait manfaat program, petani dengan jarak yang dekat dari akses informasi lebih diuntungkan dibandingkan dengan petani dengan jarak yang jauh dari akses informasi, disamping itu pula fasilitas serta dukungan lingkungan sosial cenderung lebih baik daripada petani dengan jarak yang jauh dari akses informasi. Sedangkan pada kegiatan program Kartu Tani, petani dengan jarak yang jauh dari akses informasi cenderung lebih pasif dikarenakan akses yang jauh dari dinas terkait menghambat kinerja dalam penyampaian informasi maupun kegiatan yang terkait program Kartu Tani, sehingga petani dengan jarak yang dekat dari akses informasi cenderung lebih aktif dalam kegiatan program Kartu Tani dan berdampak pada persepsi petani yang lebih baik terrhadap program Kartu Tani. Menurut Kustiari (2006) petani yang mampu berinteraksi dengan sumber inovasi/informasi seperti dengan para penyuluh, petugas dari dinas dan ketua kelompok akan berpeluang menggali informasi, mengkonsultasikan permasalahan, dan mendiskusikan hal-hal baru yang pada akhirnya dapat meningkatkan kemampuan mereka dalam berusahatani.

Perbedaan persepsi ini berarti bahwa petani dalam menilai obyek akan bergantung pada intensitas informasi yang didapat petani, petani dengan jarak yang jauh dari akses informasi 
cenderung pasif terhadap inovasi baru maupun program, artinya informasi yang didapat petani dengan jarak yang jauh dari akses informasi relatif lebih sedikit dibandingkan petani dengan jarak yang dekat dari akses informasi, disamping itu pula fasilitas yang mendukung menjadi faktor penentu dalam setiap pengambilan keputusan petani, jarak yang dekat dengan akses informasi biasanya lebih memanfaatkan fasilitas yang ada sehingga dalam mencari dan memperoleh informasi lebih cepat dan mudah.

\section{Perbedaan Persepsi Petani terhadap Program Kartu Tani Berdasarkan Kedudukan Petani di Kelompok Tani (Pengurus dengan Anggota Kelompok Tani)}

Tabel 1 menunjukkan bahwa terdapat perbedaan persepsi yang signifikan terhadap program Kartu Tani berdasarkan kedudukan petani di kelompok tani antara pengurus kelompok tani dengan anggota kelompok tani. Hal ini menunjukkan bahwa persepsi petani pengurus kelompok tani lebih baik dari persepsi petani anggota kelompok tani. Persepsi petani terhadap program Kartu Tani meliputi pengertian program, manfaat program dan kegiatan program.

Widhiningsih (2015) dalam Prihtanti (2016) peran kelompok tani (sebagai unit belajar, kerjasama, dan produksi) memberikan pengaruh positif dan signifikan terhadap inovasiadopsi

Terkait pengertian program petani pengurus kelompok tani memiliki informasi yang lebih jelas dan detail daripada petani non pengurus/anggota kelompok tani sehingga pengurus kelompok tani cederung lebih paham terkait program Kartu Tani. Pada manfaat program, pengurus kelompok tani menilai bahwa program Kartu Tani dapat memperoleh manfaat lebih banyak dibandingkan dengan anggota kelompok tani sehingga akan berpersepsi lebih baik daripada anggota kelompok tani. Sedangkan kegiatan program Karu Tani karena pengurus kelompok tani intensitas keikutsertaan dalam setiap kegiatan lebih tinggi dari anggota kelompok tani sehingga tentu pengurus kelompok tani akan memiliki persepsi yang lebih baik dari anggota kelompok tani.

Perbedaan persepsi antara pengurus kelompok tani dan anggota kelompok tani merupakan salah satu implikasi dari keaktifan petani dalam mencari dan memperoleh informasi terkait suatu inovasi baru atau program pertanian, pengurus kelompok tani cenderung lebih aktif dalam mencari informasi, diantaranya dengan melalui kegiatankegiatan yang dilakukan seperti pertemuan rutin kelompok tani dan perwakilan kelompok tani dalam sosialisasi dan pelatihan yang dilakukan oleh dinas atau instansi terkait seperti Dinas Pertanian, Bank BRI maupun Balai Penyuluhan Pertanian.

Pengurus kelompok tani biasanya lebih aktif dalam kehadiran di pertemuan kelompok tani, disamping itu pula pengurus cenderung lebih banyak mengikuti kegiatan pendidikan non formal, meliputi penyuluhan, pelatihan, kursus tani maupun kunjungan, sehingga lebih banyak informasi yang didapat dan diperoleh sehingga menjadi bahan pertimbangan petani dalam setiap pengambilan keputusan terkait suatu inovasi baru maupun program pemerintah, baik dari pemerintah pusat maupun pemerintah daerah. Hal ini didukung oleh pendapat Lionberger (1960) dalam Setiawan et al. (2006) yang menyatakan bahwa golongan masyarakat yang aktif mencari informasi dan ide-ide baru, biasanya lebih inovatif dibandingkan dengan orang-orang yang pasif apalagi berlaku skeptis (tidak percaya) terhadap sesuatu yang baru.

\section{KESIMPULAN DAN SARAN}

\section{Kesimpulan}

Terdapat perbedaan persepsi yang signifikan terhadap program Kartu Tani antara petani yang jarak aksesnya jauh dari Kantor Kecamatan dan Bank BRI dengan petani yang jarak aksesnya dekat dari Kantor Kecamatan dan Bank BRI pada taraf kepercayaan 95\%. Terdapat perbedaan persepsi yang signifikan terhadap program Kartu Tani antara pengurus kelompok tani dengan anggota kelompok tani pada taraf kepercayaan $95 \%$.

\section{Saran}

Terkait perbedaan persepsi antara petani yang jauh dari akses Kantor Kecamatan dan Bank BRI dengan petani yang dekat dari akses Kantor Kecamatan dan Bank BRI, bagi Dinas Pertanian maupun Bank BRI perlu ditingkatan dalam melakukan sosilaisasi maupun kegiatan terkait program Kartu Tani yang seimbang dan merata serta peningkatan fasilitas terkait Kartu Tani maupun pertanian bagi petani yang jauh dari akses Kantor Kecamatan dan Bank BRI sehingga dapat meminimalisir perbedaan persepsi tersebut. 
Bagi kelompok tani terkait perbedaan persepsi antara pengurus dan anggota kelompok tani, perlu meningkatan frekuensi keikutsertaan anggota dalam setiap kegiatan, disamping itu pula peran pengurus lebih di tingkatkan lagi dalam memotivasi anggota untuk aktif dalam berpartisipasi baik di pertemuan kelompok tani maupun kegiatan lainnya.

\section{DAFTAR PUSTAKA}

Achmadi, A., \& Narbuko, C. 2003. Metodologi Penelitian. Jakarta: Bumi Aksara.

Kilic, I., \& Bozkurt, Z. 2013. The Relationship between Farmers' Perceptions and Animal Welfare Standards in Sheep Farms. Asian Australas. Journal Anim. Sci. 26(9), 13291338.

Kustiari, T., Susanto, D., Sumardjo, \& Pulungan, I. 2006. Faktor-Faktor Penentu Tingkat Kemampuan Petani dalam Mengelola Lahan Marjinal (Kasus di Desa Karangmaja, Kecamatan Karanggayam, Kabupaten Kebumen, Jawa Tengah). Jurnal Penyuluhan. 2(1), 7-17.

Prihtanti, T.M. 2016. Farmer group as social determinant of farmer's perceptions on organic farming concepts and practice. RAJAR (RA Journal of Applied Research). 2(2), 407-415.

Setiawan, I.G., Putra, A., Asngari, P.S., \& Tjitropranoto, P. 2006. Dinamika Petani Dalam Beragribisnis Salak (Kasus di Kabupaten Karangasem Provinsi Bali). Jurnal Penyuluhan. 2(1), 46-52.

Suyanto, B., \& Sutinah. 2005. Metode Penelitian Sosial: Berbagai Alternatif Pendekatan. Jakarta: Kencana Prenadamedia Group. 